\title{
IMPACT OF SSB TAXES ON SALES
}

\author{
JUDIT VALL CASTELLÓ \\ UNIVERSITAT DE BARCELONA \& INSTITUT D'ECONOMIA DE BARCELONA \\ CENTRE FOR RESEARCH IN HEALTH AND ECONOMICS \\ UNIVERSITAT POMPEU FABRA
}

GUILLEM LOPEZ CASASNOVAS

DEPARTMENT OF ECONOMICS \& CENTRE FOR RESEARCH IN HEALTH AND ECONOMICS

UNIVERSITAT POMPEU FABRA

\begin{abstract}
:
In this paper, we analyze a tax on sugar-sweetened beverages (SSB) that was introduced in Catalonia on May 1, 2017. The Bill established the requirement of a $100 \%$ passthrough of the tax to the final consumer and two levels of the tax: 0.08 euro/liter for products with 5-less than 8 grams of sugar and 0.12 euro/liter for products with 8 grams of sugar or more. Previous literature focusing on the impact of SSB taxes finds that pass-though is only complete in the long-term. Our paper provides new evidence that, when the tax increases prices substantially and immediately, the sales response is also significant. In particular, we estimate that the new SSB tax in Catalonia reduced SSB purchases by $7.7 \%$. We document that part of this reduction is substituted by an increase in sales of zero/light drinks (substitution effect). Importantly, the reduction in purchases is stronger in areas with a higher incidence of obesity, in areas with higher household incomes and for products with higher sugar content.
\end{abstract}




\section{Introduction}

In most developed countries, the incidence of overweight and obesity is growing very rapidly. In OECD countries, 54\% of the adult population was overweight in 2015, and approximately $19.5 \%$ of the population was obese (see Figures 1 and 2 below, OECD Health Statistics, 2017). ${ }^{1}$ Furthermore, these conditions are a growing concern not only for the adult population but also for children. ${ }^{2}$ Higher overweight incidence among children is worrying because it will entail increases in public health problems in the future. Indeed, OECD projections show a steady increase in overweight prevalence until at least 2030 (OECD, 2017).

Consumption of sugar is considered to be one of the driving causes of the growing overweight and obesity incidence (Te Morenga et al., 2012), and part of the sugar consumption and its associated excess caloric intake comes from the consumption of sugar-sweetened beverages (SSBs). ${ }^{3}$ Block (2004) reports that the number one contributor of energy intake is soft drinks, which contributes $7.1 \%$ of energy intake in two representative surveys in the United States. In a meta-analysis summarizing the results of 32 studies, there is evidence from cohort analysis showing that an increment of one daily serving of SSBs is associated with a $0.22 \mathrm{~kg}$ weight gain in adults over one year (Malik et al., 2013). Furthermore, there is increasing evidence showing the direct link between the consumption of SSBs and numerous health problems, such as increased risk of cardiovascular diseases (coronary heart diseases and strokes, Bechthold et al., 2017), increased risk of hypertension (Schwingshackl et al., 2017), and diabetes 2 and metabolic syndrome (Malik et al., 2010). In a recently published paper using a large prospective cohort of more than 100000 participants, the consumption of sugary drinks is found to be associated with increased risk of overall cancer and breast cancer (Chazelas et al. 2019).

For all these reasons, the World Health Organization (WHO) issued a report in 2016 with a number of recommendations for governments in developed countries, such as the introduction of taxes for products that are harmful to health (with a special emphasis on those inducing noncommunicable diseases, like diabetes, obesity, and cardiovascular

\footnotetext{
${ }^{1}$ These figures are much higher for some countries: for example, the USA, where $70 \%$ of the adult population is overweight and $38 \%$ is obese.

2 In the OECD $23 \%$ of boys and $21 \%$ of girls are overweight (see Figure 3, OECD 2014).

3 Block G. Foods contributing to energy intake in the US: data from NHANES III and NHANES 1999-2000. J Food Compos Anal. 2004;14(3-4):439-447.

Reedy J, Krebs-Smith SM. Dietary sources of energy, solid fats, and added sugars among children and adolescents in the United States. J Am Diet Assoc. 2010;110(10): 1477-1484.
} 
problems) and encouraging the consumption of fruits and vegetables in individuals' diets (WHO, 2016). Following the recommendation of the WHO, governments (either national, regional, or municipal) are creating taxes on these products with the aim of reducing their consumption and improving population health both in the short- and the long-term. Mexico (in 2014), France (in 2012), and some states in the USA (Berkeley in 2015 and, more recently, Seattle, Philadelphia, Boulder, and Oakland), which have all introduced taxes on sugar-sweetened beverages (SSB), are examples of this very recent trend.

In March 2017, the Parliament of Catalonia, one of the 19 regions in Spain, approved a tax on SSB's - the tax was implemented in Catalonia in May 2017. ${ }^{4}$ The aim of the tax, as in the other countries that have implemented such a tax, was to foster the reduction in the consumption of these drinks. The amount of the tax depends on the sugar content of the drink (0.08 euro/liter for products with 5-less than 8 grams of sugar and 0.12 euro/liter for products with 8 or more grams of sugar) and is paid by the distributer. The law established that the whole increase in price had to be translated to the final consumer (100\% pass-through to final prices). In this paper, we present the first evaluation of the tax on SSB sales in Catalonia. We use data from a large supermarket chain that represents $10 \%$ of the Catalan market. Using data on final prices, we first provide evidence that is generally consistent with a full pass through of the tax to the final consumer as required by the law. We next focus on sales and show that the new SSB tax in Catalonia reduced SSB purchases by $7.7 \%$. We also document that part of this reduction was substituted by an increase in the sales of zero/light drinks (substitution effect). Furthermore, the reduction in purchases was stronger in areas with a superior incidence of obesity, in areas with higher income and for products with higher sugar content. Finally, as the amount of the tax is different according to the sugar content of the product, we show that the estimated reduction in SSB purchases (7.7\%) is entirely driven by products containing 8 grams or more of sugar, which are more heavily taxed. Thus, the implied price elasticity for those products amounts to -0.509 as the mean increase in prices is $15.10 \%$. Therefore, for a $10 \%$ increase in prices, the quantity of SSB products with 8 grams of sugar or more decreases by $5.09 \%$.

Our paper provides new evidence that, when the increase in prices is substantial, the sales response is also large.

\footnotetext{
${ }^{4}$ Several studies had advocated in favor of higher taxes for SSB's in Spain: Lopez Cassanovas (2013), Gil, LopezCasasnovas and Mora (2013), and Ortun, Gonzalez, and Pinilla (2016), among others.
} 
The pass-through rate, that is to say, the extent to which the tax is shifted to the final prices paid by consumers, is one of the most relevant aspects for policymakers before they can assess the effectiveness of the tax in reducing consumption (beyond the secondary goal of obtaining revenues). Pass-through rates vary across products, brands, regions, and package sizes.

There are some studies examining different experiences, such as the case of Mexico, where an excise tax on SSBs was introduced in 2014. A recent study on the SSB tax in Mexico reports that, on average, the tax was entirely passed through to final prices but with stronger changes for small packages, with over-shifting in carbonated SSBs and under-shifting in noncarbonated SSBs (Colchero et al., 2015). Another experience that has been studied at some length is the case of Berkeley (California), where the government of the city introduced an excise tax on SSBs in 2015. In this case, there is evidence of greater variability in the pass-through of the tax, with the average being $43.1 \%$ in the short-term. Factors such as distance to city's border, package size, and retailers make this percentage vary substantially (Cawley et al., 2017). Similar results are found by Falbe et al. (2015), who, in studying the Berkeley case, observe large variations depending on the type of product, brand, and retailer, with the average estimated pass-through rate being approximately $47 \%$ also in the short-term. On the contrary, the study by Silver et al. (2017) includes information on prices, sales and consumption of SSB's one year after the introduction of the tax in Berkeley. The authors find that, in the long-term (first year) pass-through is complete in supermarkets and chain gas stations, pass-through is partial in pharmacies while it is negative in independent corner stores and independent gas stations. Europe also has some examples. In Denmark, some changes in the taxes on beverages (also alcoholic drinks) have been introduced. Focusing on the evolution of prices after those changes, Bergman and Hansen (2016) find that the pass-through is close to one, but there are differences across products; beer and soda seem to have lower pass-through rates, while liquors have higher pass-through rates. Interestingly, the authors find heterogeneous responses in price changes for tax cuts and for tax increases: tax cuts are mostly not translated into price reductions, whereas tax hikes do increase prices. The distance to the German border also influences the pass-through rate, like in the Berkeley case. The closest example to the Catalan tax is a soda tax set in France in 2012. The tax targeted not only beverages containing sugar but also light beverages containing sweeteners. Berardi et al. (2016) estimate price changes at the product level and find that after six months the tax 
is completely passed-through for soda drinks while there is a significant under-shifting of the tax to prices of flavored waters $(62 \%)$ and $94 \%$ for fruit drinks. They also report important variability depending on the retailer. Different results are found by Etilé et al. (2017), who also analyze the French soda tax but follow a different approach: to account for substitution effects, they estimate joint index prices for SSBs and NCSBs (noncalorically sweetened beverages) instead of looking at prices at the product level. Their results are lower than those reported by Berardi et al. (2016), as they estimate a pass-through rate of $30 \%$ for SSBs and $32.6 \%$ for NCSBs.

The Catalan law obliges retailers to shift the entire tax to final prices so that the passthrough rate is a less important outcome to analyze. In any case, we will also provide evidence that is generally consistent with a full pass through of the tax to the final consumer as required by the law. Therefore, the most relevant issue in the Catalan tax is the evaluation of the extent to which the increase in prices affects the sales of SSBs. Previous literature focusing on changes in consumption after the introduction of taxes on SSBs reports ambiguous results. Taxes on sweetened drinks and snacks in Maine (introduced in 1991) and on a wide range of soft drinks in Ohio (introduced in 2003), have been found not to alter the consumption of either sugar or fat. In Maine, prices remained unchanged (both at the brand and at the aggregate level), which would explain the lack of consumption responses. In Ohio, prices changed marginally, although these changes were small and potentially not attributable to the tax, which can also explain the lack of consumption responses in this case (Colantuoni \& Rojas, 2015). On the other hand, Harding \& Lovenheim (2017) use a large transaction-level data set for a representative sample of US consumers to calculate price and expenditure elasticities. They then simulate the demand response to the introduction of product taxes on soda, SSBs, packaged meals, and snacks and of nutrient taxes on fat, salt, and sugar. They find larger impacts of nutrition than of product taxes (as they avoid substitution effects), and, in particular, sugar taxes are highlighted as being an important tool in inducing healthier choices among consumers. Finally, Fletcher et al. (2010a) exploit state variation in the USA in excise taxes, sales taxes, and special exemptions from sales taxes for the case of soft drinks to evaluate their impact on body mass index, obesity, and overweight. Their results show that state-level taxes on soft drinks in the USA have a small impact on behavior and weight (a decrease in overweight and obesity rates of approximately $0.02 \%$ and $0.03 \%$, respectively). The authors claim that the small effects 
of soft drink consumption on weight is reasonable, given that soft drinks represent $7 \%$ of the total energy intake and that tax rates are small.

In a related paper, Fletcher et al. (2010b) estimate demand functions for soft drinks with US data to evaluate the impact of state soft drink sales and excise taxes on child and adolescent consumption of soft drinks. Based on these two types of taxes, they find that soft drink taxation leads to a moderate reduction of soda consumption by children and adolescents. However, they also report that this moderate reduction in soft drinks consumption is completely offset by increases in the consumption of other high-calorie drinks (such as juice and juice-related drinks and whole milk). More specifically, they report that a 1 percentage point increase in soft drinks tax rates increases caloric intake from milk by $13 \%$. The presence of these substitutes offsets the reduction of caloric intake due to less soda consumption, so there is no evidence that a tax on soft drinks reduces overall caloric intake. Conversely, Finkelstein et al. (2013) use data from the 2006 Homescan panel to estimate the potential impact of the introduction of an SSB tax that would increase prices by $20 \%$. They consider both the impact on SSB consumption and the impact on the consumption of 12 other food categories, and they find a reduction of $24.3 \mathrm{kcal}$ per day per person and no substitution to other sugary foods as a result of such a tax.

As shown in our above review, the existing literature on the impact of SSB taxes on consumption is not very extensive, as the use of fiscal policies to reduce the consumption of SSBs is a relatively new issue. Of course, some less-specific sales and excise taxes already existed in a number of countries, but the new taxes targeting specifically SSB products have been in place only over the last decade. Therefore, we contribute to this new literature in several dimensions. First, we study the first SSB tax that requires a $100 \%$ transfer to the final consumer, which is something not included in previous SSB taxes introduced in France, Mexico, or Berkeley. This requirement increases the final prices of SSB drinks substantially and immediately, especially for the case of big containers that experience increases in prices of more than $20 \%$ as a result of the tax. This price increase is in line with the recommendations of the WHO for SSB taxes to be effective. Second, we provide evidence that this immediate increase in prices is translated into important reductions in SSB's sales. Furthermore, we run several heterogeneity tests to understand the types of regions and consumers that prove to be more responsive to the tax. Finally, we also explore the response for potential substitutes. We believe that our results are informative not only for policymakers that 
plan to introduce similar taxes in other countries but also for countries that have recently introduced the tax, such as the United Kingdom, Ireland, and South Africa.

\section{The Catalan Tax on sugar-sweetened drinks}

On March 22, 2017, the Catalan Parliament enacted a tax on SSBs, which has been included in law (5/2017). ${ }^{5}$ This tax was planned to come into force on April 1, 2017, but, given that its implementation required changes in the receipt systems of the companies, the final introduction of the tax was delayed until May 1, 2017. The tax affects the consumption of SSBs in the entire Catalan territory independently of the place where the SSBs have been produced.

The aim of this tax is to reduce the consumption of these beverages, given the negative effects of excessive sugar consumption on population health. This objective is in line with the recommendation issued by the WHO in a report from October 2016 encouraging governments to tax SSBs to reduce obesity and diabetes problems (WHO, 2016).

According to the law, SSBs are all those beverages containing caloric added sweeteners, such as sugar, honey, fructose, sucrose, or several types of syrups (rice, corn, agave...). This includes soda drinks, fruit juices, sport drinks, teas and coffees, energetic drinks, sweetened milks and shakes, vegetable drinks, and flavored waters. Any kind of beverage that does not contain added caloric sweeteners is not taxed. Other beverages excluded from the tax are drinkable yogurts, drinkable fermented milks, products used for medical reasons, and alcoholic drinks (see Table 2).

The Bill establishes that the tax is paid by the person (legal or physical) providing the beverage to the final consumer; that is to say, retailers, bars and restaurants, cinemas, vending machines, etc. However, the distributor may act as the payer of the tax under some circumstances (even the producers can be the payers of the tax in cases of direct sales), always under the premise that the tax must be transferred $100 \%$ to the final consumer. This is, in fact, how it generally works in practice. The distributor, which is a much more concentrated market, is the one paying the taxes and transferring them to its clients - retailers, bars, and restaurants, etc. To do so, the distributor must include the tax in the invoice under the concept "IBEE" (Impost de Begudes Ensucrades Envasades), SSB tax in Catalan. The tax must be included in the VAT tax base.

\footnotetext{
${ }^{5}$ Published in the DOG n. 7340 , the $30^{\text {th }}$ of March
} 
In our case, the supermarket chain is the single and direct tax payer. The tax base is the quantity, in liters of SSB, supplied to the consumer. The tax rate varies depending on the quantity of sugar contained in the beverage. Products with less than 5 grams of sugar per 100 milliliters are exempt from the tax. For drinks containing between 5 and less than 8 grams of sugar per 100 milliliters, the tax is 0.08 euros per liter. For drinks containing at least 8 grams per 100 milliliters, the tax is 0.12 euros per liter (see Table $1)$.

The tax is payable from the moment the consumer has purchased the product.

Table 1 . Summary of the price increases regulated by the law.

\begin{tabular}{|l|l|}
\hline \multicolumn{1}{|c|}{ Grams of sugar per 100ml } & \multicolumn{1}{c|}{ Tax per liter } \\
\hline 0-less than 5 & Exempt \\
\hline 5-less than 8 & $0.08 €$ \\
\hline 8 or more & $0.12 €$ \\
\hline
\end{tabular}

Table 2. Products taxed and nontaxed.

\begin{tabular}{|l|l|}
\hline \multicolumn{1}{|c|}{ Products taxed } & \multicolumn{1}{c|}{ Products not included } \\
\hline & \\
-Soda drinks & -Natural fruit or vegetable juices \\
-Fruit juices or fruit nectars & -Milk or milk-derived drinks not containing \\
-Sport drinks & added caloric sweeteners \\
-Teas and coffees & -Drinkable yogurts \\
-Energetic drinks & -Drinkable fermented milks \\
-Sweetened milks, shakes, and juices & -Alcoholic drinks \\
containing milk. & \\
-Vegetable drinks & \\
-Flavored waters & \\
\hline
\end{tabular}

\section{Data}

We have data of one big supermarket chain operating throughout the Catalan territory that has $10 \%$ of the Catalan market share. We have weekly data on the total number of sales by type of product (at the individual level for 71 products (barcodes) comprising SSBs of different brands (41 of the 71 products/barcodes) and zero/light products from 
different brands (30 of the 71 products/barcodes)) from week 7 to week 32 and for the years 2016 and 2017. We have this information for each of the stores that the supermarket chain has in Catalonia (approximately 160 stores). We also have detailed information on the location of the store, which will allow us to aggregate the information for groups of stores placed in the same region to explore heterogeneous effects by income level, and other characteristics of the region. Thus, we create 18 different income-level regions according to the Family Available Gross Income (RFDB) data provided by the Catalan Statistical Office (IDESCAT) (for the municipalities and the counties) and by Barcelona's Town Hall (for the Barcelona Districts), (see Table 1A in the Appendix). Thus, we will explore the existence of heterogeneous responses to the tax along the family income dimension. In order to do that, we split the sample in three groups according to the location of the supermarkets; if the supermarket is located in one of the first 11 regions in Table 1A we classify them in the low income region group; if the supermarket is located in regions $12,13,14,15,16$ or 17 in Table $1 \mathrm{~A}$ we include them in the middle income region group. Finally, if the supermarket is located in region 18 we consider them as belonging to the high income region group. As can be seen in Table 1A there is a substantial jump in family income from region 17 to region 18 which prompts us to estimate region 18 separately. This classification ensures a similar number of observations in the low and middle income groups while, at the same time, allowing for a specific separate analysis for the richest region (region 18).

Moreover, we analyze the potential heterogeneous response to the introduction of the tax along one additional geographical dimension, using regions with higher obesity rates and regions with lower obesity rates. As explained above, the main aim of the tax is to reduce SSB consumption to improve population health and decrease the negative health consequences associated with excessive consumption of sugar. Thus, if we find that the tax was most effective in areas with higher obesity rates, we have reasons to think that there could be potentially positive effects of the tax on population health. To do that, we use data from the Catalan Health Survey (ESCA) in 2016, and we collect information on the percentage of the population who are obese for the seven sanitary regions in Catalonia. We divide the sample between supermarkets located in regions with a higher obesity rate - Lleida, with a $15.4 \%$ obesity incidence, Alt Pirineu/Aran, with a $16 \%$ obesity incidence, Camp de Tarragona, with a $17 \%$ obesity incidence, and Terres de l'Ebre, with a $19 \%$ obesity incidence - and supermarkets located in areas with a lower obesity rate but excluding the Barcelona area-Catalunya Central, with a 
$15 \%$ obesity rate and Girona, with a $15 \%$ obesity rate (See Table $2 \mathrm{~A}$ in the appendix). Finally, we consider the Barcelona region separately, even if it also has a lower obesity incidence of $14 \%$, because of the different characteristics of the city and its population size (almost half of the population in Catalonia are located in the Barcelona area).

We collect information on the grams of sugar per liter of product for the 71 products, and we group them into two groups of products: 1) SSBs, if the product has 5 or more grams of sugar per $100 \mathrm{ml}$ and 2) zero/lights, if the product has less than 5 grams of sugar per 100ml. Only the first group of products, SSBs, is subject to the tax.

We also classify products according to the size of the container. That is, products with a container of 0.5 liters or less are classified as "small container". On the contrary, if the product is stored in a container of more than 0.5 liters we classify them as "big container". This is important, because the size of the container is a key variable in explaining the percentage increase in the price due to the law; big containers are usually cheaper than small containers (for the same product), and they include the same amount of sugar per $100 \mathrm{ml}$ (which determines the increase in the price as dictated by the law). Therefore, this may result in different behavioral responses of consumers according to the size of the container due to the different percentage increases in prices for small and big containers.

Additionally, to corroborate that the introduction of the tax was fully transferred to the final consumer, as stated by the law, we also have information on prices of each of the products: one observation with the price of all 71 products one month before the introduction of the reform, and one observation with the price of all 71 products one month after the introduction of the reform.

\section{Econometric Strategy \& Results}

\subsection{Price changes}

As explained above, we only have information of prices at one point in time before the law (one month before) and one point in time after the law (one month after) for the 71 products included in our sample. Therefore, we calculate the increase in prices between these two points in time for these products. Figure 4 shows the increase in price in percentages by total liters of the product. In order to calculate that, we use the average price increase of all products with the same total liters and the same grams of sugar. 
Thus, for example we plot the average price increase of all SSB products of 0.5 liters that have a given amount of sugar content. As can be seen, there is almost no change in prices for zero/light products of any size, which is consistent with those products not being subject to the SSB tax. On the other hand, we can see that, for all sizes, there is an increase in the prices of SSB products. Furthermore, the increase in prices is higher for some of the products that contain two and four liters of SSBs. More specifically, prices increase between 5-10\% for products in smaller containers (cans) and by approximately $20 \%$ for larger products. This is in line with the WHO recommendation, which establishes that retail prices should increase by $20 \%$ or more for the SSB tax to result in sizeable reductions in consumption (WHO, 2016). In fact, Figure 4 shows that, for SSBs of two and four liters, the price increases by almost $25 \%$ on average.

To understand whether the price increase observed in Figure 4 corresponds to the increase dictated by the law, in Figure 5 we compare the real increase in prices observed in our data with the increase stated by the law. The figure shows a solid line, in which we calculate the average price change dictated by the tax according to two characteristics: total liters (size of the container) and grams of sugar that the product contains. The dots, on the other hand, show the real increase in the price of the products observed in our data, and we plot them (averaging) also according to these two characteristics (liters and grams of sugar).

The first thing to highlight is that the real increase in price is almost identical to the price increase dictated by the law. This is true for all products expect for four SSB items that have more than 8 grams of sugar. Again, there is no change in prices for nontaxed zero/light products. Therefore, we conclude that the required pass-through rate of a $100 \%$ was enforced for most of the SSBs subject to the tax and, for some products (especially SSBs in big containers), the increase in the final price was remarkably high. This fact suggests that the change in sales can also be large.

This requirement in the Catalan law is a unique feature, as SSB taxes implemented in other countries do not establish a pass-through rate by law.

\subsection{Changes in purchasing behavior}

After providing evidence that the change in price was relatively large, particularly so for SSBs in big containers, and that other nontaxed products did not experience a change in 
prices, we next explore the potential changes in sales patterns brought about by the implementation of the tax.

We start by looking at some descriptive evidence on the evolution of sales patterns for 2017 and compare them with sales patterns for 2016 (from week 7 to week 32) separately for SSBs and zero/light products.

Figure 6 shows that the purchases of SSBs was higher in 2017 than in 2016. However, after the tax was introduced in May 2017, the sales of SSBs dropped and reached the same level than 2016. Thus, it seems that the tax equalized the sales of SSBs in 2016 and 2017. It is also important to note that, in the two weeks preceding the introduction of the policy, there was a strong increase in purchases of SSBs. From week 25 (18-24 June) onwards there was again an increase in the sales coinciding with the beginning of the summer holidays (week 25 is the last week of school in Spain). For zero and light products, Figure 7 shows that sales were much higher in 2017 than in 2016, which is consistent with the fact that people become progressively more aware of the need to consume sugar-free products. As the difference between 2016 and 2017 is much larger for lights/zeros than for SSB it is difficult to visually compare the evolution of the purchases of both types of products.

Thus, we now turn to the econometric model to estimate the effects of the introduction of the tax on purchasing behavior. We estimate a separate model for each of the two types of products (SSBs and zero/lights) comparing purchasing behavior in the weeks after the introduction of the tax policy in 2017 (May 1) to the one in the weeks before the introduction and to the same pattern in 2016, which allows us to control for any seasonality trends affecting only SSBs and zero/light products.

Thus, the model that we estimate is as follows:

$$
P_{i w y s}=\alpha+\beta_{3} \text { post }_{w} * 2017+\gamma_{s}+\vartheta_{i}+\theta_{y}+\delta_{w}+\delta_{w} * \theta_{y}+\varepsilon_{i t s}
$$

"P" are the purchases of product " $i$ " in week "w" of year " $y$ " and store "s". "Post" is a dummy variable that takes the value 1 for weeks starting on May 1, and "2017" is another dummy variable taking the value of 1 for 2017. We control for fixed effects of store (supermarket), product, week, year and week-by-year. We estimate this model separately for SSBs and zero/lights. Therefore, the interaction between "Post" and "2017" will capture any changes in the purchases of SSBs (or zero/lights products) in 
the weeks after the introduction of the tax with respect to the weeks before the tax and in comparison with the same difference in 2016.

Table 4 shows that the purchases of SSBs are reduced by 2.37 liters per product, establishment, and week. At the same time, in the second column of Table 4, we observe that the purchases of zero/light products increase by 7 liters per product, establishment, and week. Thus, there is a degree of substitution in the sales of SSBs towards zero and light products. As the mean in SSBs sales before the reform per establishment, product, and week amounts to 30.48 liters, the reduction of 2.37 liters represents an impact of the reform amounting to $7.7 \%$. Furthermore, as we have approximately 160 establishments in our sample, and 41 products (out of the 71) are SSBs, we estimate a reduction in SSB sales of 15,547 liters per week. As our data come from a supermarket chain that represents almost $10 \%$ of the Catalan market, our estimates suggest that the SSB tax reduced the sales of SSB products by $159,260^{6}$ liters per week, which is a non-negligible quantity. With respect to light and zero products, we estimate an increase in sales of 33,600 litres per week ${ }^{7}$ so that around $21 \%$ of the reduction in SSB's purchases is substituted by an increase in light/zero products.

We also perform several heterogeneity tests to understand the characteristics of the SSB products and the types of consumers that are more affected by the introduction of the SSB tax.

Table 5 reports the results of the same model, but for a sample of establishments located in high/middle/low-income regions in Catalonia (see Table 3 and the data section for more detail on this categorization). The effects go in the same direction in all the regions, although the magnitude of the effect is bigger in the higher income regions. We estimate that the purchases of SSBs were reduced by 5.56 liters per product, establishment, and week in the highest income region (an impact of $29.5 \%$ with respect to the mean), while in middle and low income regions the reduction in SSBs sales was of 1.34 and 1.55 liters respectively (an impact of $4.2-4.5 \%$ with respect to the mean).

Table 6 shows the results by type of container. We can see that the size of the coefficient is significant and negative for both SSB's in small and big containers. Also, the size of the estimated reduction in sales is also similar in both cases, although slightly bigger for SSB's in big recipients, which is consistent with the findings in the previous section for prices, which showed that SSBs in big containers were subject to larger

\footnotetext{
${ }^{6}$ This corresponds to 2.37 liters* 160 establishments*41 products.

${ }^{7}$ This corresponds to 7 liters* 160 establishments*30 products.
} 
increases in prices as a result of the tax. We find increases in light/zero products for both small and big containers.

As the amount of the tax is different according to the sugar content of the product, in Table 7 we explore whether the reductions in purchases are stronger for products more heavily taxed. In the first column of Table 7 we observe that the tax has no significant impact for products containing 5-less than 8 grams of sugar whereas in the second column, we estimate a drop in SSB's sales for products with 8 grams of sugar or more. The former products are subject to a reduced tax of 0.08 euros per liter while the latter products are subject to a tax of 0.12 euros per liter. Thus, the higher the tax the stronger the consumers' response. More specifically, the tax reduces the purchases of SSB products with 8 grams of sugar or more by $7.7 \%$ (-2.505 liters over a mean consumption of 32.48) so that the entire reduction in consumption as a result of the tax is driven by products with a higher sugar content. As the mean increase in prices for those products is $15.10 \%$ after the tax, the implied price elasticity is -0.509 ; so that for a $10 \%$ increase in prices, purchases are reduced by $5.09 \%$.

To further explore the potential existence of different responses in the territory, we perform the estimation dividing the sample along an alternative dimension.

As the target of the tax is the reduction in SSBs sales due to the negative health impacts of excessive sugar consumption, in Table 8 we present the results for regions with a higher/lower obesity rate (see Table $2 \mathrm{~A}$ in the appendix for a description of this classification as well as the data section). We estimate the baseline model for three different groups: a group of regions with higher obesity rates, a group of regions with lower obesity rates but excluding Barcelona and a group which only includes the Barcelona region, which also has lower obesity rates. We estimate the Barcelona region separately as there are many differences with respect to the other regions along several dimensions and, in particular, this region includes a very large part (half) of the total population in Catalonia. ${ }^{8}$ It can be seen that regions with a higher obesity rate respond strongly with a sizeable reduction in SSB as a result of the introduction of the tax. In particular, SSB sales are reduced by 5 liters in regions with a higher incidence of obesity (a $14.5 \%$ with respect to the mean), whereas the result is not significant for lower obesity regions. In Barcelona we estimate a reduction in SSB sales of 3.56 liters,

\footnotetext{
${ }^{8}$ If we include Barcelona in the low obesity regions, the estimate results for the regression of Barcelona are showing up for the models pulling all low obesity regions, which may be misleading because, as we see in Table 8, only Barcelona shows the significant reduction in SSB consumption.
} 
which represents a significantly smaller effect than the one reported in high obesity regions. Thus, even if we do not have data on health outcomes, the result of a stronger drop in SSB purchases in areas with a higher incidence of obesity points towards potential long-term positive effects on health outcomes of the introduction of the tax. Therefore, although the impact of the tax is significant throughout the Catalan territory, we report stronger effects in regions with a higher incidence of obesity.

\subsection{Robustness checks}

We next present a series of robustness checks to assess the strength of our results. As can be seen in Figures 6 and 7, which plot the evolution of SSB and light/zero sales in 2017 versus 2016, there is a remarkable spike in week 16 of 2017, just before the tax comes into effect. If we analyze the same behavior in the previous year, 2016, we can see that there is no such spike in week 16 in the year before the introduction of the tax. The increase in purchases is, thus, most likely due to the imminent introduction of the tax. This hypothesis is reinforced when we look at Figure 9, which plots Google trend searches for the word "sugar tax" in both Catalan and Spanish languages. We can see a strong increase in those searches for the same weeks before the tax is introduced. Therefore, our first robustness check is to assess the validity of our results when we drop weeks 16 and weeks 16 and 17 to avoid capturing any of these anticipation and stock-piling effects in the purchases of SSBs.

Table 9 shows the results after dropping week 16 only (first two columns) or after dropping both weeks 16 and 17 (last two columns) from our analysis. In the two tests, we estimate almost the same exact coefficients for both SSB's and light/zero products than in our baseline models in Table 4. Both the sizes as well as the significant levels are almost exactly the same than in our baseline results. Therefore, we conclude that our results are not dependent on potential anticipation effects of consumers, who seem to increase their purchases of SSB products in the weeks before the tax is implemented.

Although it is reasonable to say that our results are consistent with the tax changing purchases of both SSBs and their substitutes (lights/zero products), as a final robustness check, we estimate a differences-in-differences model in which we compare the sales of SSB products against zero/light products before and after the week of May 1st in 2017 against the same change both before and after the week of May 1, 2016. Even if light/zero drinks are not a "good" control group, we still want to show this specification, 
as it allows us to control for any similar sales patterns for these types of drinks that may occur in 2017 but not in 2016. In particular, the model that we estimate is

$$
P_{i w y s}=\alpha+\beta_{3} \text { post }_{w} * 2017 * S S B+\gamma_{s}+\vartheta_{i}+\theta_{y}+\delta_{w}+\delta_{w} * \theta_{y}+\varphi S S B+\varepsilon_{i t s}
$$

As before, $P$ is the purchases of product "i" in week "w" of year " $y$ " and store "s". "SSB" is a dummy variable that refers to taxed products (sugar-sweetened drinks), "Post" is a dummy variable that takes the value 1 for weeks starting on May 1 , and "2017" is another dummy variable taking the value of 1 for 2017 . We control for fixed effects of store (supermarket), product, week, year and week-year.

Table 10 shows that, compared to the purchasing behavior of zero/light products, the purchases of SSBs decreased by almost 2.64 liters per week, product, and supermarket establishment. The impact of the tax estimated with this diff-diff model is somewhat bigger, as it incorporates both the reduction in SSB sales and the increases in light/zero drinks. Thus, with respect to the mean of SSB sales, we estimate a reduction by $8.6 \%$. Overall, the results of the diff-diff model reinforce the conclusions of our main findings of important decreases in SSB purchases as a result of the introduction of the tax.

\section{Conclusions}

In 2016, the World Health Organization (WHO) issued a report that called for the introduction of taxes on sugar-sweetened beverages in developed countries. In particular, the WHO recommended that the tax should result in an increase in retail prices by $20 \%$ or more to be effective in reducing consumption. In this paper, we analyze the impact of a sugar-sweetened beverage (SSB) tax introduced in Catalonia in May 2017 that required, by law, a 100\% pass through of the tax to the final consumer. Therefore, final prices were effectively increased by more than $20 \%$ for SSBs for big containers ( 2 liters) and by approximately $5-10 \%$ for small containers (cans). Although SSB taxes have been recently introduced in other developed countries, such as the United Kingdom (2018), Ireland (2018), South Africa (2018), Mexico (2014), and France (2012), and in some cities in the USA (2015 in Berkeley and later on in Seattle, Philadelphia, Boulder, and Oakland), none of these previous taxes included the requirement of a $100 \%$ pass-through to the final consumer. Thus, the evidence shows 
that in these other countries, the pass-through was less than $100 \%$ in the short-term and only reached a $100 \%$ in the long-term.

Our results show that SSBs sales decreased by $7.7 \%$ across the territory, but the reduction was much more pronounced for regions with higher incomes and for products with higher amounts of sugar content. The implied price elasticity for products with a higher sugar content amounts to -0.509 . Therefore, for a $10 \%$ increase in prices, the quantity of SSB products with 8 grams of sugar or more decreases by $5.09 \%$

This effect is partly substituted by an increase in zero/light drinks (substitution effect), whose prices remained stable, as they were not affected by the tax. At the same time, our results show that the impact is stronger in areas with a higher incidence of obesity. Therefore, there is scope for considering that the tax may lead to improvements in health outcomes in the middle/long term.

It is important to note that our data come from a supermarket chain that covers the entire territory but represents $10 \%$ of the total Catalan market. However, if we assume that the purchasing behavior would be similar for consumers in other supermarkets, we can use our estimates to develop a back-of-the-envelope calculation of the amount of grams of sugar and the corresponding calories that are saved as a result of the tax. Our baseline models show a reduction in SSB sales of 159,260 liters per week (see the results' section above). We know that each gram of sugar contains 4 calories, and we can assume that SSB's have an average of 8 grams of sugar per $100 \mathrm{ml}$. Thus, the reduction in SSB sales saves 12,740,800 grams of sugar per week. From the Catalan Health Survey (2016 wave) we know that $22 \%$ of the population in Catalonia drinks SSBs on a daily basis $(5,462,000$ inhabitants aged $20-80$ in Catalonia in 2016) which entails a reduction of 42 calories on average per person per week. This result is not very different from the one in Finkelstein et al. (2013) paper which, using scan data, report a decrease in $24.3 \mathrm{kcal}$ per day per person from the introduction of a simulated SSB tax that would increase SSB prices by $20 \%$.

Even if our analysis only covers the short-run effect of the policy (three months of postreform data), we believe that our results are informative not only for policymakers who plan to introduce similar taxes in other countries but also for countries that have just implemented the tax, such as the United Kingdom, Ireland, and South Africa. 


\section{REFERENCES}

Bechthold A, et al. (2017). Food groups and risk of coronary heart disease, stroke and heart failure: a systematic review and dose-response meta-analysis of prospective studies. Crit Rev Food Sci Nutr 1-20.

Berardi N, Sevestre P, Tepaut M, Vigneron, A. (2016). The impact of a 'soda tax' on prices.Evidence from French micro data. Applied Economics, 48, No. 41; 3976-3994.

Bergman U.M, Hansen N.L. (2016). Are Excise Taxes on Beverages Fully Passed Through to Prices? The Danish Evidence. Danmarks Nationalbank Working Paper

Block G. (2004). Foods contributing to energy intake in the US: data from NHANES III and NHANES 1999---2000. J Food Compos Anal. 2004;14(3-4):439-447.

Cawley J, Frisvold D.E. (2017). The Pass-Through of Taxes on Sugar-Sweetened Beverages to Retail Prices: The Case of Berkeley, California. Journal of Policy Analysis and Management, Vol. 36, No. 2, 303-326.

Chazelas E, Srour B, Desmetz E, Kesse-Guyot E, Julia C, Deschamps V, DruesnePecollo N, Galan P, Hercberg S, Latino-Martel P, Deschasaux M, Touvier M. (2019). Sugary drink consumption and risk of cáncer: results from NutriNet-Santé prospective cohort. BMJ; 365.

Colantuoni F, Rojas C. (2015). The Impact Of Soda Sales Taxes On Consumption: Evidence From Scanner Data, Contemporary Economic Policy (ISSN 1465-7287)

Vol. 33, No. 4, October 2015, 714-734, doi:10.1111/coep.12101

Colchero MA, Salgado JC, Unar-Munguía M, Molina M, Ng S, Rivera-Dommarco JA (2015). Changes in Prices After an Excise Tax to Sweetened Sugar Beverages Was Implemented in Mexico: Evidence from Urban Areas. PLoS ONE 10(12):

e0144408. doi:10.1371/journal.pone.0144408

Etilé F, Lecocq S, Boizot-Szantaï C. (2017). The Incidence of Soft Drink Taxes on Consumer Prices and Welfare: Evidence from the French \Soda Tax". Working Paper.

Falbe J, Rojas N, Grummon A.H, Madsen K.A. (2015). Higher Retail Prices of SugarSweetened Beverages 3 Months After Implementation of an Excise Tax in Berkeley, California. American Journal of Public Health;105:2194-2201. doi:10.2105/AJPH.2015.302881

Finkelstein E.A, Zhen C, Bilger M, Nonnemaker J, Farooqui A.M, Todd J.E. (2013). Implications of a sugar-sweetened beverage (SSB) tax when substitutions to nonbeverage items are considered. Journal of Health Economics; 32: 219-239.

Fletcher J, Frisvold D.E, Tefft N. (2010a). Can Soft Drink Taxes Reduce Population Weight?. Contemporary Economic Policy (ISSN 1465-7287) Vol. 28, No. 1, January, 2010, 23-35, doi:10.1111/j.1465-7287.2009.00182.x 
Fletcher J, Frisvold D.E, Tefft N. (2010b). The effects of soft drink taxes on child and adolescent consumption and weight outcomes. Journal of Public Economics 94, 967974, doi:10.1016/j.jpubeco.2010.09.005

Gil J, López Casasnovas G, Mora T. (2013). Taxation of unhealthy consumption of food and drinks: An updated literature review, Hacienda Pública Española, IEF, vol. 207(4).

Harding M, Lovenheim M. (2017). The effect of prices on nutrition: Comparing the impact of product-and nutrient-specific taxes. Journal of Health Economics, http://dx.doi.org/10.1016/j.jhealeco.2017.02.003

López Casasnovas G. (2013). ¿Cambia la fiscalidad y los estilos de vid? Impuestos para luchar contra la obesidad. Rev Esp Salud Pública, 87:541-548. Nº 6 NoviembreDiciembre

Malik V.S, Pan A, Willett W.C, Hu F.B. (2013). Sugar-sweetened beverages and weight gain in children and adults: a systematic review and meta-analysis. American Journal of Clinical Nutrition, 98:1084-102.

Malik VS, Popkin BM, Bray GA, Després JP, Willet WC, Hu FB. (2010). Sugarsweeteened beverages and risk of metabolic syndrome and type 2 diabetes: a metaanalysis. Diabetes Care: 33: 11: 2477-83.

OECD (2014). Obesity and the economics of prevention: Fit not Fat, Key facts-Spain, Update 2014. Link: https://www.oecd.org/spain/Obesity-Update-2014-SPAIN.pdf

OECD (2017). Obesity Update 2017. Link: http://www.oecd.org/health/obesityupdate.htm

Ortún V, López-Valcárcel B, Pinilla J. (2016). El impuesto sobre bebidas azucaradas en España. Rev Esp Salud Pública, 90: 9-140.

Reedy J, Krebs-Smith SM. (2010). Dietary sources of energy, solid fats, and added sugars among children and adolescents in the United States. J Am Diet Assoc: 110(10): 1477---1484.

Schwingshackl L, et al. (2017). Food groups and risk of hypertension: A systematic review and dose-response meta-analysis of prospective studies. Advances in Nutrition: 8: 6: 793-803.

Silver LD, Ng SW, Ryan-Ibarra S, Teillie LS, Induni M, Miles DR, Poti JM, Popkin BM. (2017). Changes in prices, sales, consumer spending, and beverage consumption one year after a tax on sugar-sweetened beverages in Berkeley, California, US: A before-and-after study. PLoS Med 14(4).

Te Morenga L, Mallard S, Mann J. (2012). Dietary sugars and body weight: a systematic review and meta-analysis of randomized controlled trials and cohort studies. British Medical Journal: 346. 
WHO (2016). Fiscal Policies for Diet and Prevention of Noncommunicable Diseases: technical meeting report, 5-6 May 2015, Geneva, Switzerland. 


\section{FIGURES AND TABLES}

Figure 1. Adult overweight rates in selected countries.

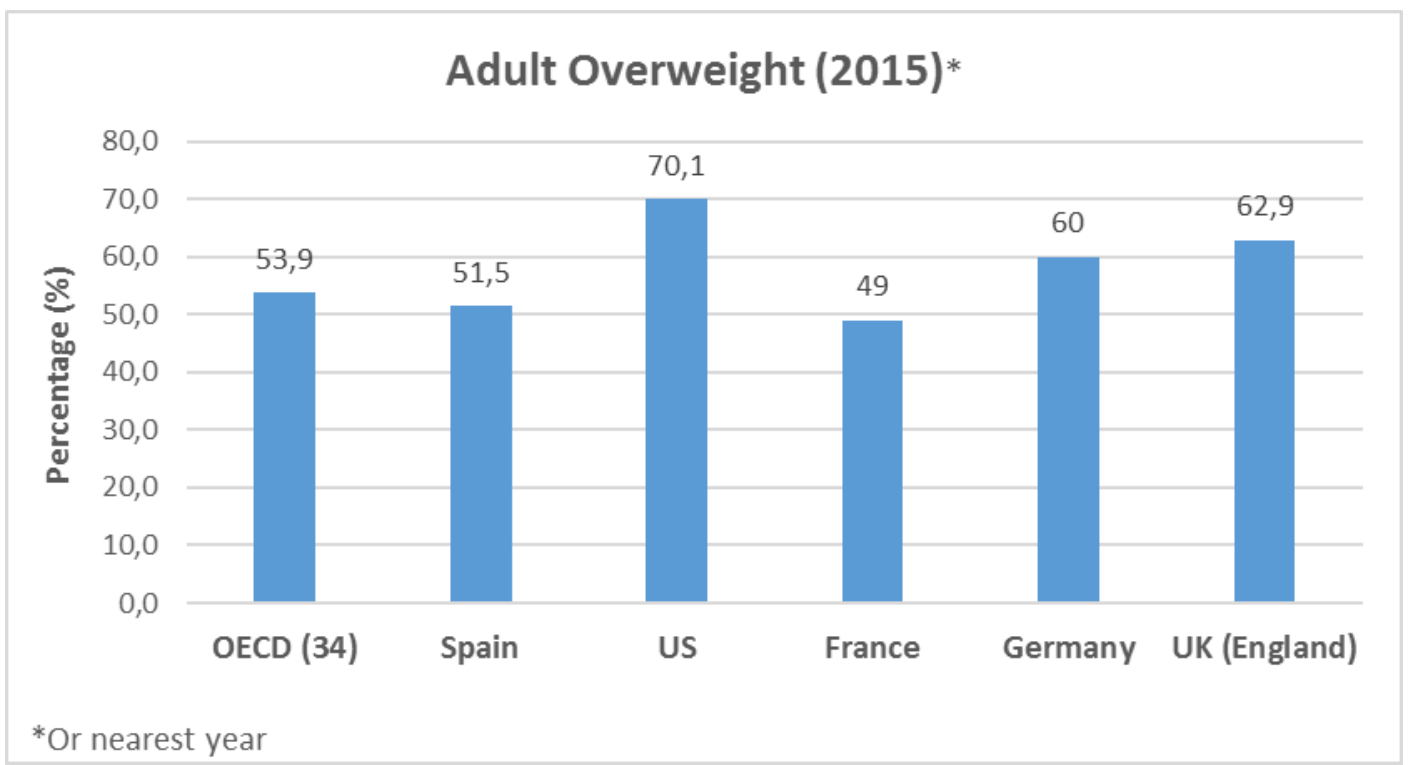

Source: OECD Health Statistics 2017.

Figure 2. Adult obesity rates in selected countries.

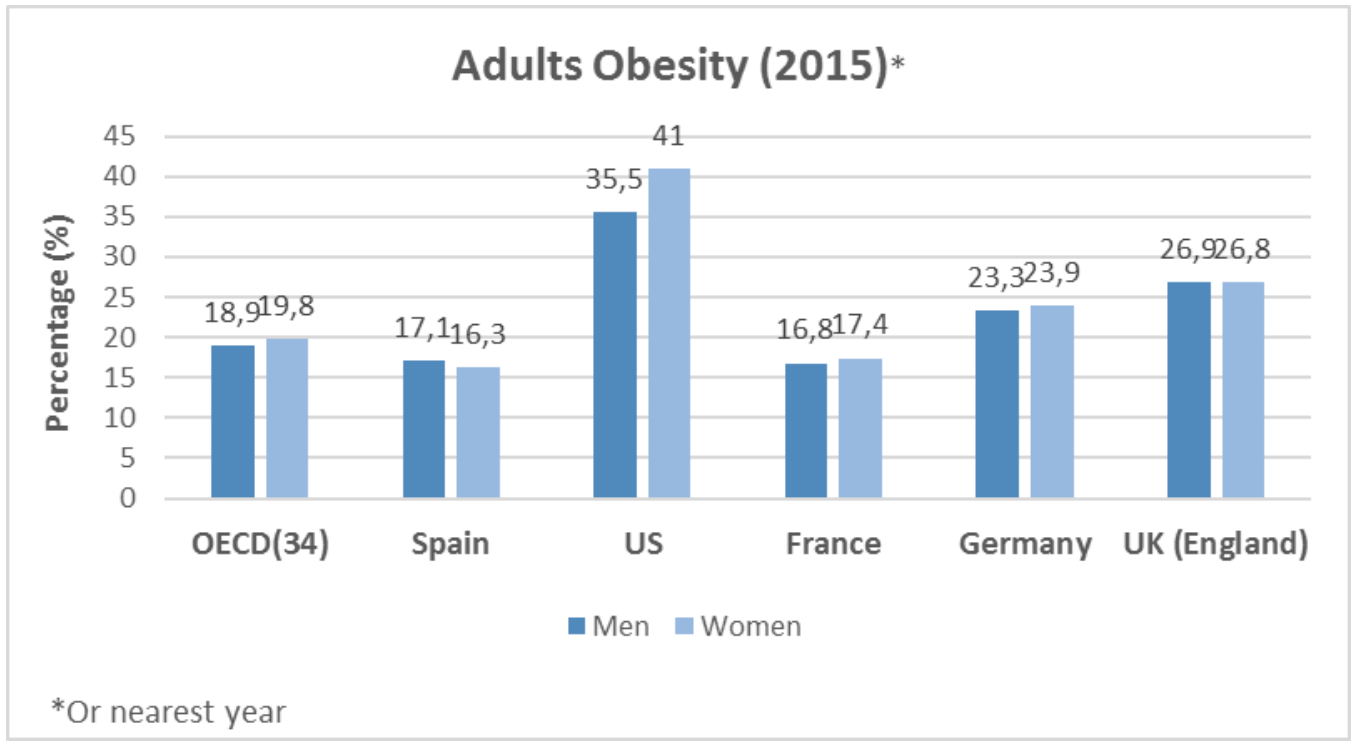

Source: OECD Health Statistics 2017. 
Figure 3. Children's overweight rates in selected countries.

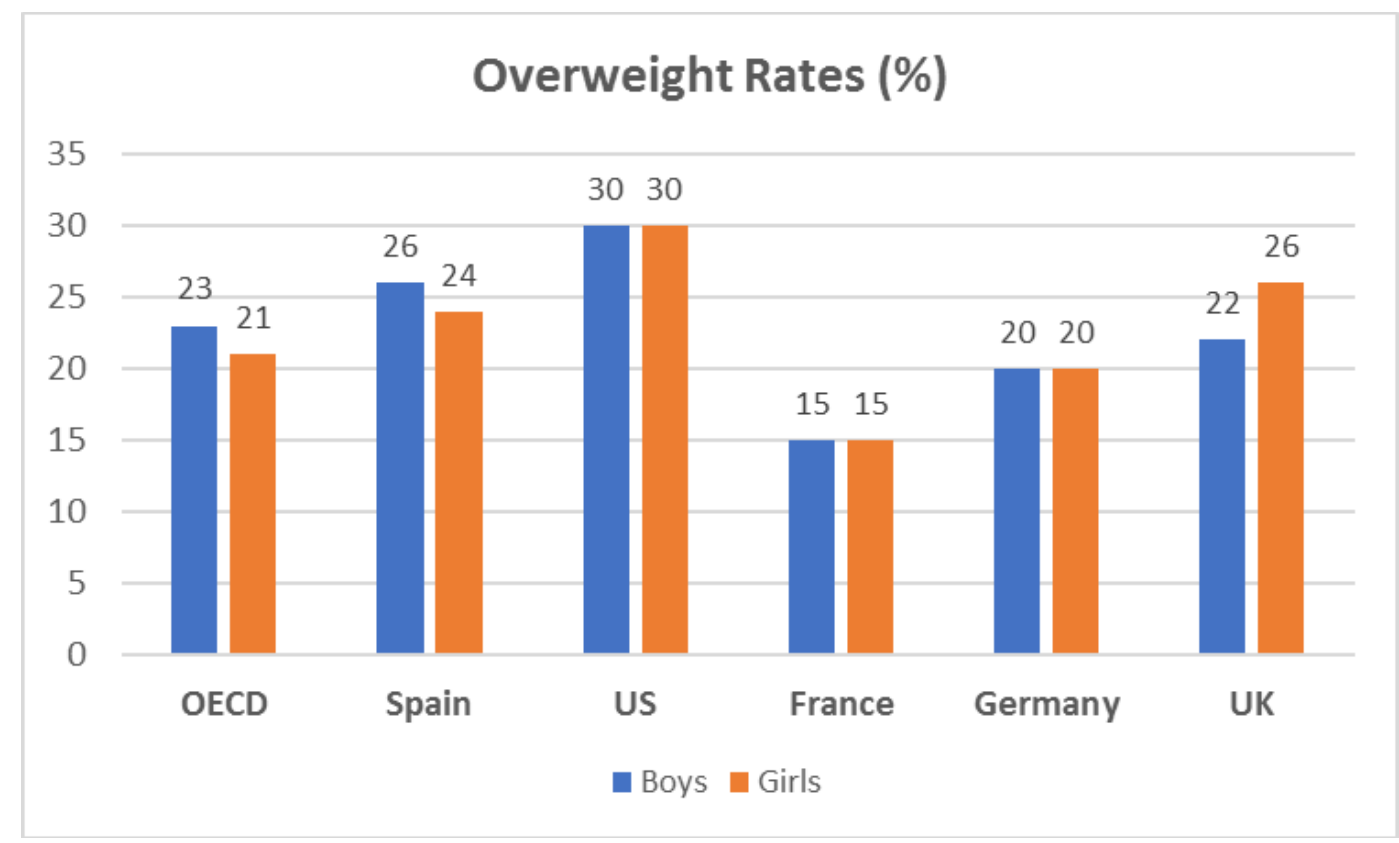

Source: OECD Report (2014).

Figure 4. Price change in percentage by total liters of the product.

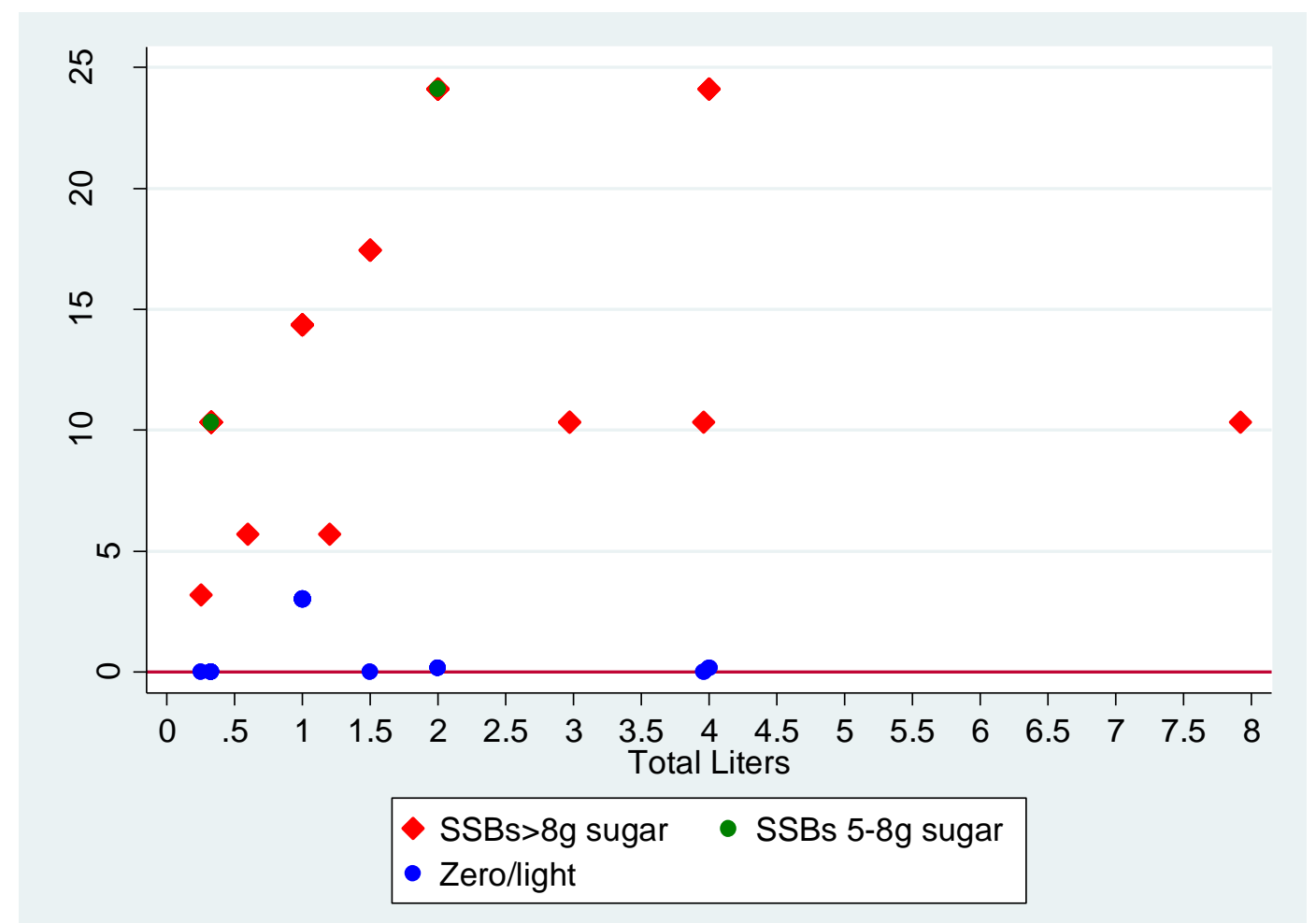

Source: Author's own calculation using data on prices for 71 selected products one month before the introduction of the SSB tax and one month after the introduction of the tax. Price changes have been calculated as averages of all products with the same total liters and the same sugar content. 
Figure 5. Price change in euros by total liters of the product.

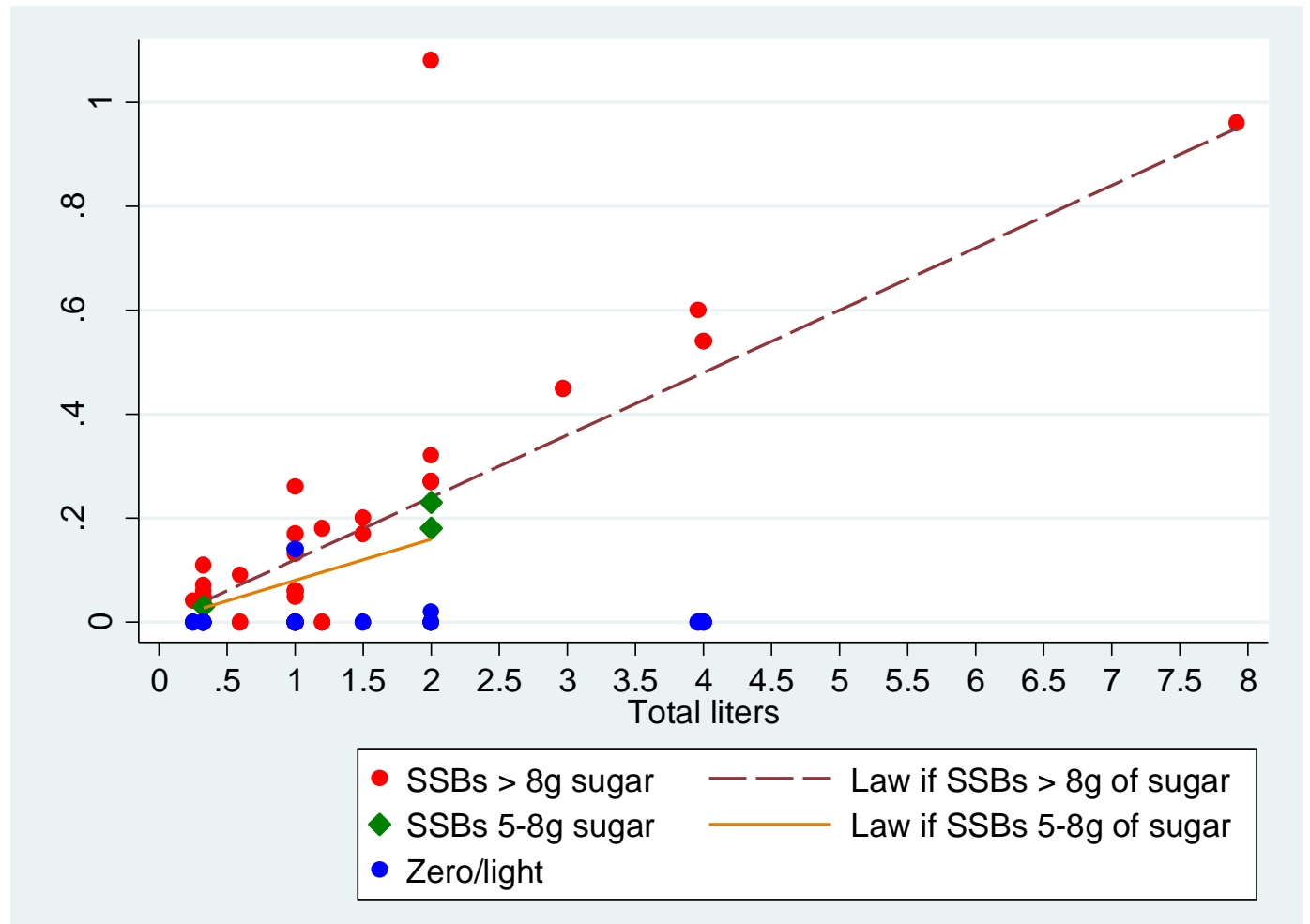

Note: The solid and dashed lines represent the average price increase dictated by the law depending on the content of sugar and the size of the container of group of products. The other elements represent the real average increase in prices observed in our data for each group of products (with the same total liters and the same sugar content).

Source: Author's own calculation using data on prices for 71 selected products one month before the introduction of the SSB tax and one month after the introduction of the tax. Price changes have been calculated as averages of all products with the same total liters and the same sugar content.

Table 3. Mean, maximum, and minimum family available gross income by high/middle/low income regions.

\begin{tabular}{|cccc|}
\hline Income Region & $\begin{array}{c}\text { Family Income } \\
\text { (In thousand } € \text { ) }\end{array}$ & Max & Min \\
\hline Low & 11.09 & 14.90 & 10.12 \\
Middle & 15.90 & 18.90 & 15 \\
High & 26.25 & 33.60 & 19.91 \\
\hline
\end{tabular}

Source: IDESCAT (Catalan Statistical Institute). 
Table 4. Total Purchased Liters. 2016 vs 2017.

Week $>18 \&$ Year $==2017$

Constant

Mean Dependent Variable

Observations

R-squared

Product FE

Supermarket FE

Year*Week FE

Robust standard errors in parentheses

$* * * \mathrm{p}<0.01, * * \mathrm{p}<0.05, * \mathrm{p}<0.1$
SSBs

Zero/Light

$$
-2.370 * * *
$$

$-0.749$

$(0.765)$

$-15.98 * * *$

(1.075)

30.48

20.55

284,464

216,267

0.511

0.493

YES

YES

YES

YES

YES

YES

Note: The dependent variables are the purchases of (1) SSB's, and (2) zero/light products per week, year, and supermarket. Regressions include product, supermarket and year-week fixed effects. The tax is introduced in week 18 of the year 2017. The dataset includes weeks 7 to 32 of years 2016 and 2017. Standard errors are clustered at the supermarket level. 
Table 5. Total Purchased Liters — High/Middle/Low Income Regions. 2016 vs 2017.

\begin{tabular}{lcccccc}
\hline & \multicolumn{2}{c}{ High Income Regions } & \multicolumn{2}{c}{ Middle Income Regions } & \multicolumn{2}{c}{ Low Income Regions } \\
\hline & SSBs & Zero/Light & SSBs & Zero/Light & SSBs & Zero/Light \\
\hline & & & & & & \\
Week>18 \& & & & & & \\
Year==2017 & $-5.563^{* * *}$ & 0.00488 & -1.346 & $6.131^{* * *}$ & -1.557 & $11.22^{* * *}$ \\
& $(0.913)$ & $(1.207)$ & $(1.011)$ & $(0.893)$ & $(1.379)$ & $(1.522)$ \\
Constant & $7.135^{* * *}$ & $-4.534 * *$ & 0.134 & $-15.44 * *$ & $10.18^{* * *}$ & $-9.410^{* * *}$ \\
& $(1.883)$ & $(1.816)$ & $(1.860)$ & $(1.485)$ & $(2.390)$ & $(1.901)$ \\
& & & & & & \\
Mean Dependent & & & & & & \\
Variable & 18.8 & 19 & 31.7 & 22.7 & 34 & 22.7 \\
& & & & & & \\
Observations & 34,363 & 28,603 & 133,505 & 100,115 & 116,596 & 87,549 \\
R-squared & 0.634 & 0.631 & 0.544 & 0.530 & 0.503 & 0.464 \\
Product FE & YES & YES & YES & YES & YES & YES \\
Supermarket FE & YES & YES & YES & YES & YES & YES \\
Year*Week FE & YES & YES & YES & YES & YES & YES \\
\hline
\end{tabular}

Robust standard errors in parentheses

$* * * \mathrm{p}<0.01, * * \mathrm{p}<0.05, * \mathrm{p}<0.1$

Note: The dependent variables are the purchases of (1) SSB's, and (2) zero/light products in high/middle/low income regions per week, year, and supermarket. Regressions include product, supermarket and year-week fixed effects. The tax is introduced in week 18 of the year 2017. The dataset includes weeks 7 to 32 of years 2016 and 2017. Standard errors are clustered at the supermarket level. 
Table 6. Total Purchased Liters — Big/Small containers. 2016 vs. 2017.

\begin{tabular}{lcccc}
\hline & \multicolumn{2}{c}{ Big Container } & \multicolumn{2}{c}{ Small Container } \\
& SSBs & Zero/Light & SSBs & Zero/Light \\
\hline & & & & \\
Week>18 \& Year==2017 & $-2.723^{* *}$ & $7.945^{* * *}$ & $-2.704^{* * *}$ & $5.718^{* * *}$ \\
& $(1.086)$ & $(0.851)$ & $(0.950)$ & $(1.560)$ \\
Constant & 0.180 & $-5.227^{* * *}$ & $73.60^{* * *}$ & $30.65^{* * *}$ \\
& $(1.265)$ & $(0.677)$ & $(2.570)$ & $(1.435)$ \\
Mean Dependent & & & & \\
Variable & & & & \\
& 34.89 & 20.69 & 25.11 & 20.35 \\
Observations & & & & \\
R-squared & 154,508 & 125,492 & 129,956 & 90,775 \\
Product FE & 0.510 & 0.512 & 0.526 & 0.503 \\
Supermarket FE & YES & YES & YES & YES \\
Year*Week FE & YES & YES & YES & YES \\
\hline
\end{tabular}

Robust standard errors in parentheses

$* * * \mathrm{p}<0.01, * * \mathrm{p}<0.05, * \mathrm{p}<0.1$

Note: The dependent variables are the purchases of (1) SSB's, and (2) zero/light products in big/small containers per week, year, and supermarket. Regressions include product, supermarket and year-week fixed effects. The tax is introduced in week 18 of the year 2017. The dataset includes weeks 7 to 32 of years 2016 and 2017. Standard errors are clustered at the supermarket level. 
Table 7. Total Purchased Liters — High/Low Sugar Content. 2016 vs 2017.

\begin{tabular}{lcc}
\hline & \multicolumn{2}{c}{ SSBs } \\
\hline & $5-8$ gr. sugar & 8-more gr. sugar \\
Week>18 \& Year==2017 & 0.541 & $-2.505^{* * *}$ \\
& $(0.882)$ & $(0.800)$ \\
Constant & $-6.089^{* * *}$ & -1.835 \\
& $(0.850)$ & $(1.398)$ \\
& & \\
Mean Dependent Variable & 13.00 & 32.48 \\
& & \\
Observations & 20,715 & 263,749 \\
R-squared & 0.462 & 0.510 \\
Product FE & YES & YES \\
Supermarket FE & YES & YES \\
Year*Week FE & YES & YES \\
\hline
\end{tabular}

Robust standard errors in parentheses

$* * * \mathrm{p}<0.01, * * \mathrm{p}<0.05, * \mathrm{p}<0.1$

Note: The dependent variables are the purchases of (1) SSB products with 5-8 grams of sugar, and (2) SSB products with more than 8 grams of sugar per week, year, and supermarket. Regressions include product, supermarket and year-week fixed effects. The tax is introduced in week 18 of the year 2017. The dataset includes weeks 7 to 32 of years 2016 and 2017. Standard errors are clustered at the supermarket level. 
Table 8. Total Purchased Liters — High/Low Obesity Rate Regions. 2016 vs 2017.

\begin{tabular}{lcccccc}
\hline & \multicolumn{2}{c}{ High Obesity } & \multicolumn{2}{c}{$\begin{array}{c}\text { Low Obesity (no } \\
\text { Barcelona) }\end{array}$} & \multicolumn{2}{c}{$\begin{array}{c}\text { Low Obesity: } \\
\text { Barcelona }\end{array}$} \\
\hline & SSBs & Zero/Light & SSBs & Zero/Light & SSBs & Zero/Light \\
\hline Week>18 \& & & & & & & \\
Year==2017 & $-4.951^{*}$ & $7.342^{* * *}$ & -0.249 & $10.14^{* * *}$ & $-3.561^{* * *}$ & $3.727 * * *$ \\
& $(2.433)$ & $(1.994)$ & $(0.899)$ & $(1.149)$ & $(0.885)$ & $(0.973)$ \\
Constant & $18.04^{* * *}$ & $-9.878^{* *}$ & $-4.355^{*}$ & $-13.81^{* * *}$ & $9.609 * * *$ & $-8.949^{* * *}$ \\
& $(3.613)$ & $(3.615)$ & $(2.304)$ & $(1.723)$ & $(1.526)$ & $(1.367)$ \\
Mean Dependent & & & & & & \\
Variable & 34.4 & 23.5 & 34.1 & 20.7 & 26.2 & 23 \\
& & & & & & \\
Observations & 50,106 & 38,726 & 121,761 & 88,531 & 112,597 & 89,010 \\
R-squared & 0.535 & 0.477 & 0.507 & 0.480 & 0.565 & 0.547 \\
Product FE & YES & YES & YES & YES & YES & YES \\
Supermarket FE & YES & YES & YES & YES & YES & YES \\
Year*Week FE & YES & YES & YES & YES & YES & YES \\
\hline Robustar & & & & &
\end{tabular}

Robust standard errors in parentheses

$* * * \mathrm{p}<0.01, * * \mathrm{p}<0.05, * \mathrm{p}<0.1$

Note: The dependent variables are the purchases of (1) SSB's, and (2) zero/light products in regions with a higher or lower obesity rate per week, year, and supermarket. The third and fourth columns are low obesity regions excluding Barcelona while the fifth and sixth columns belong only to Barcelona, which is a low obesity region. Regressions include product, supermarket and year-week fixed effects. The tax is introduced in week 18 of the year 2017. The dataset includes weeks 7 to 32 of years 2016 and 2017. Standard errors are clustered at the supermarket level. 
Table 9. Robustness check: Total Purchased Liters. 2016 vs 2017. Week 16 dropped and weeks $16 \& 17$ dropped.

\begin{tabular}{lcccc}
\hline & \multicolumn{2}{c}{ Week 16 dropped } & \multicolumn{2}{c}{ Weeks 16 \& 17 dropped } \\
& SSBs & Zero/Light & SSBs & Zero/Light \\
\hline \multirow{2}{*}{ Week>18 \& Year==2017 } & $-2.325^{* * *}$ & $7.056^{* * *}$ & $-2.361^{* * *}$ & $7.012^{* * * *}$ \\
& $(0.752)$ & $(0.766)$ & $(0.753)$ & $(0.764)$ \\
Constant & -0.650 & $-16.10^{* * *}$ & -1.003 & $-16.13^{* * *}$ \\
& $(1.371)$ & $(1.092)$ & $(1.341)$ & $(1.094)$ \\
& & & & \\
Observations & 273,917 & 207,936 & 262,788 & 199,445 \\
R-squared & 0.512 & 0.493 & 0.509 & 0.491 \\
Product FE & YES & YES & YES & YES \\
Supermarket FE & YES & YES & YES & YES \\
Year*Week FE & YES & YES & YES & YES \\
\hline
\end{tabular}

Robust standard errors in parentheses

$* * * \mathrm{p}<0.01, * * \mathrm{p}<0.05, * \mathrm{p}<0.1$

Note: The dependent variables are the purchases of (1) SSB's, and (2) zero/light products per week, year, and supermarket. Regressions include product, supermarket and year-week fixed effects. The tax is introduced in week 18 of the year 2017. The dataset includes weeks 7 to 32 of years 2016 and 2017. In the first two columns week 16 is dropped while in columns 3 and 4 weeks 16 and 17 are dropped. Standard errors are clustered at the supermarket level. 
Table 10. Robustness check: Diff in Diff: SSBs against zero/light products.

\section{SSBs vs Zero}

Week $>18 \&$ Year==2017 \& SSB==1

Constant

Observations

R-squared

Product FE

Robust standard errors in parentheses

$* * * \mathrm{p}<0.01, * * \mathrm{p}<0.05, * \mathrm{p}<0.1$

Note: The dependent variable is the purchases of (1) SSB's and zero/light products per week, year, and supermarket. Regressions include product, supermarket and year-week fixed effects. The tax is introduced in week 18 of the year 2017. The dataset includes weeks 7 to 32 of years 2016 and 2017. Standard errors are clustered at the supermarket level. 
Figure 6. SSBs, 2016-2017.

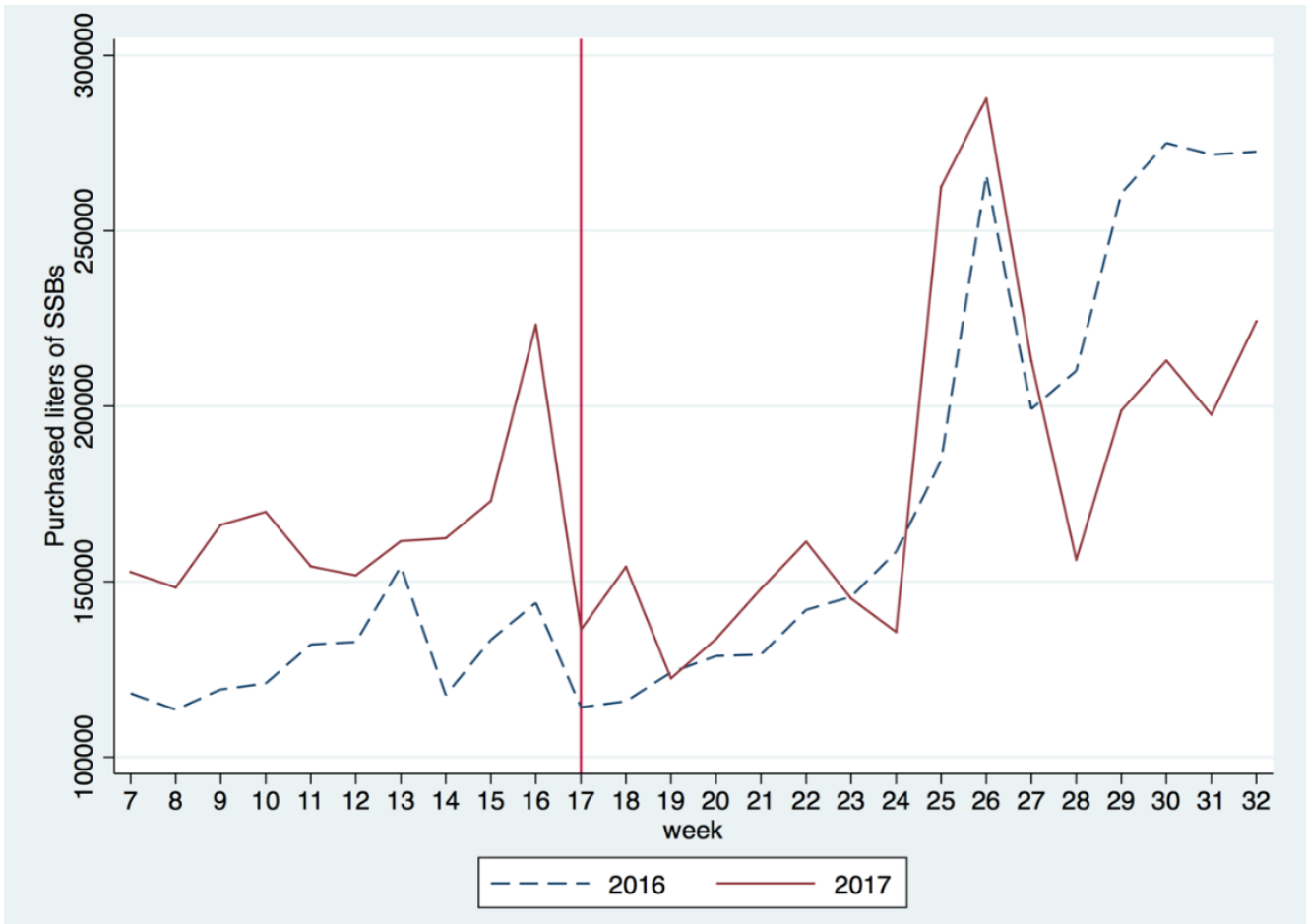

Source: Author's own calculation using data on total liters purchased of SSB products in 2016 (dashed line) and 2017 (solid line) for weeks 7 to 32 in 2016-2017. Data come from a supermarket chain that has a $10 \%$ market share of the Catalan market. The vertical line denotes tax implementation.

Figure 7. Zero and Light Beverages, 2016-2017.

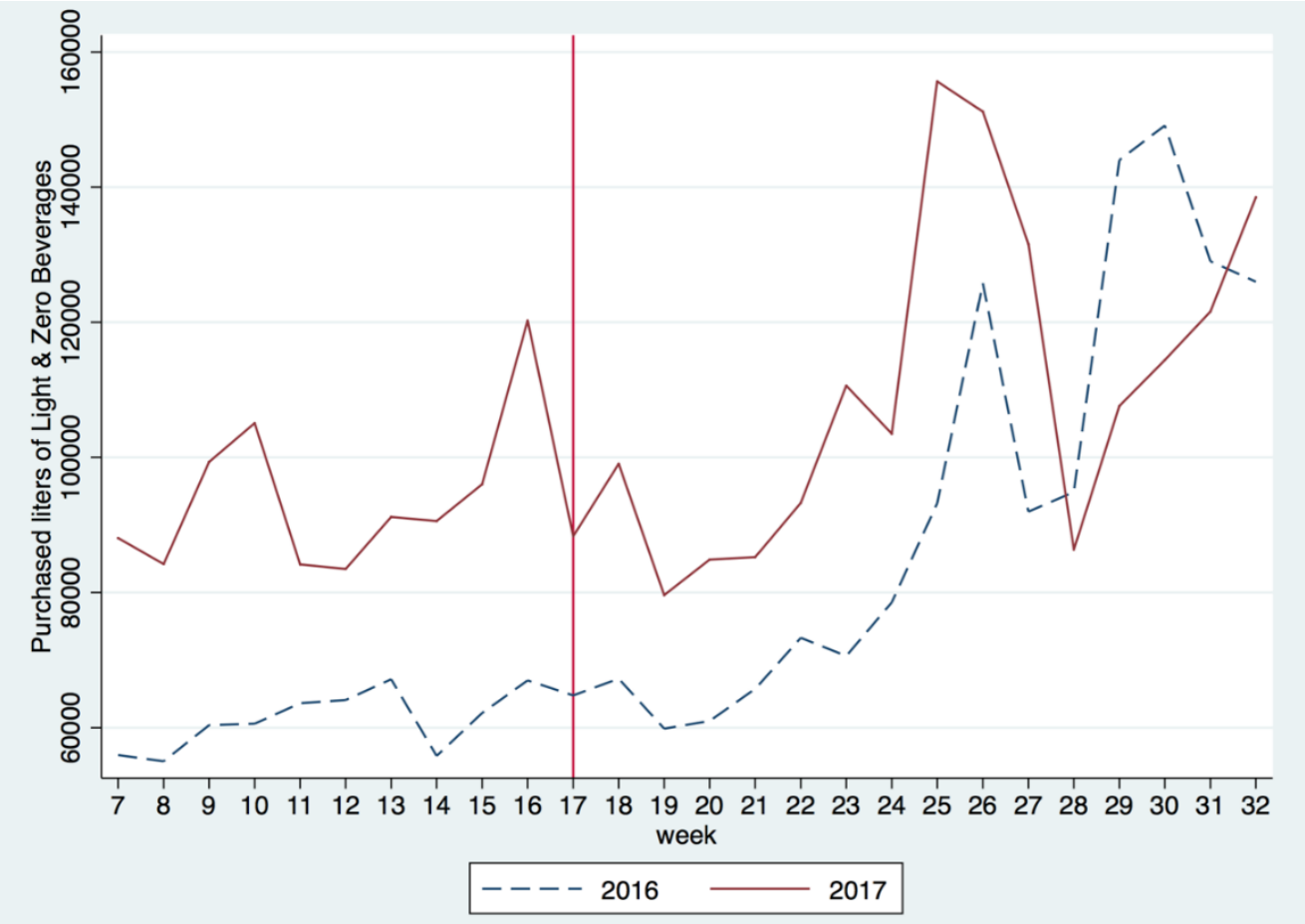

Source: Author's own calculation using data on total liters purchased of zero/light products in 2016 (dashed line) and 2017 (solid line) for weeks 7 to 32 in 2016-2017. Data come from a supermarket chain that has a $10 \%$ market share of the Catalan market. The vertical line denotes tax implementation. 
Figure 9. Google trend searches for sugar tax in the two official languages: Spanish and Catalan.

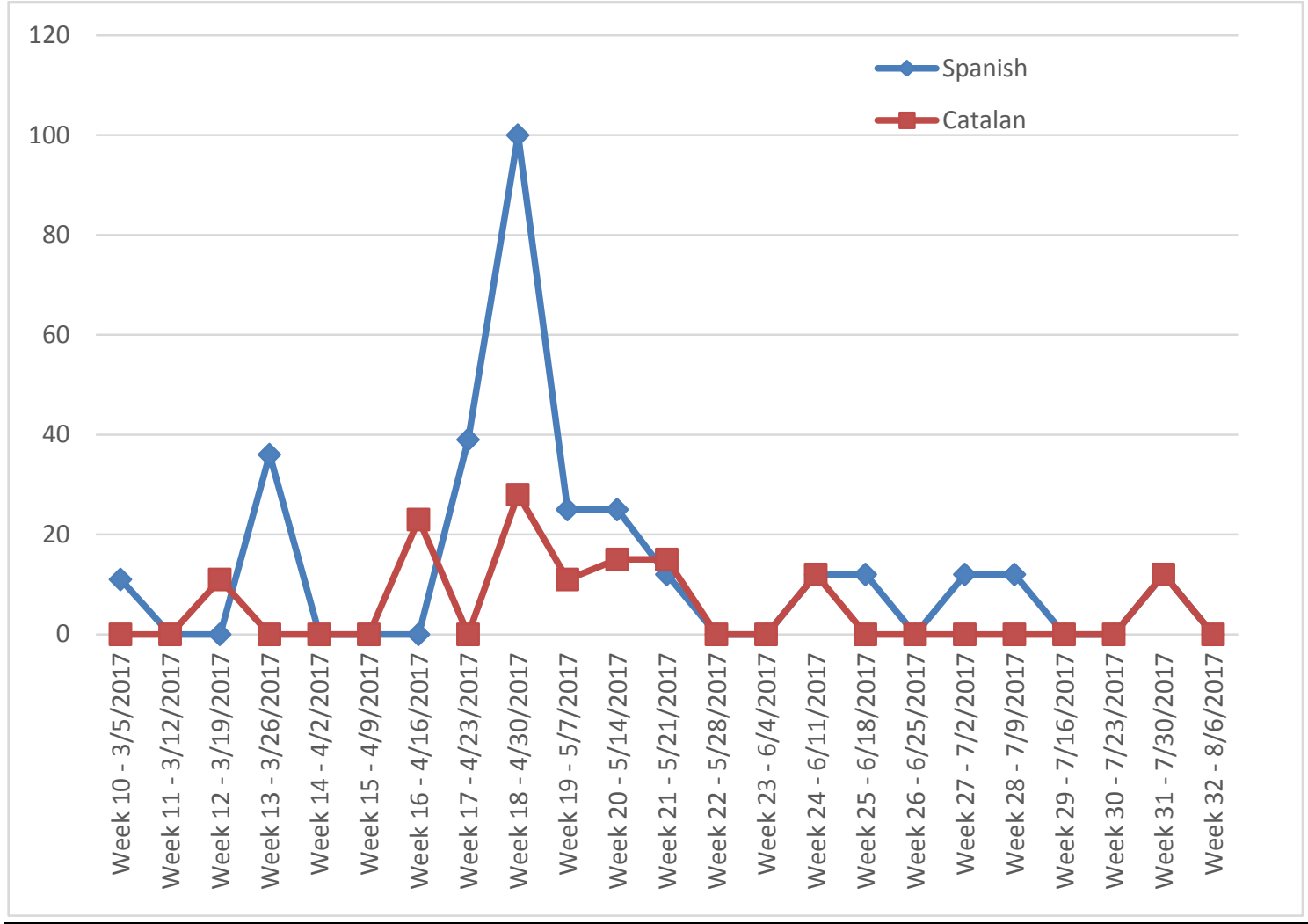

Source: Google trends. 


\section{APPENDIX}

Table 1A. Family Income Groups.

\begin{tabular}{|c|c|c|c|c|}
\hline $\begin{array}{l}\text { Income } \\
\text { Group }\end{array}$ & $\begin{array}{c}\text { Comarques/ } \\
\text { Municipalities/ } \\
\text { Districts }\end{array}$ & $\begin{array}{c}\text { Family Income (in } \\
\text { thousands } € \text { ) }\end{array}$ & $\begin{array}{c}\text { Family Income } \\
\text { Max }\end{array}$ & $\begin{array}{c}\text { Family Income } \\
\text { Min }\end{array}$ \\
\hline 1 & $\begin{array}{l}\text { Nou Barris } \\
\text { Montsià } \\
\text { Baix Ebre }\end{array}$ & 11.14 & 12.10 & 10.12 \\
\hline 2 & $\begin{array}{l}\text { Alt Empordà } \\
\text { Alt Urgell } \\
\text { Baix Empordà }\end{array}$ & 12.87 & 13.20 & 12.70 \\
\hline 3 & $\begin{array}{c}\text { Selva } \\
\text { Terra Alta } \\
\text { Urgell }\end{array}$ & 13.33 & 13.40 & 13.20 \\
\hline 4 & $\begin{array}{c}\text { Sant Andreu (BCN) } \\
\text { Baix Penedès } \\
\text { Noguera }\end{array}$ & 13.47 & 13.50 & 13.40 \\
\hline 5 & $\begin{array}{l}\text { Sants-Montjuic (BCN) } \\
\text { Solsonès } \\
\text { Pla d'Urgell }\end{array}$ & 13.62 & 13.70 & 13.55 \\
\hline 6 & $\begin{array}{c}\text { Ciutat Vella }(\mathrm{BCN}) \\
\text { Garrigues } \\
\text { Priorat }\end{array}$ & 13.97 & 14.00 & 13.90 \\
\hline 7 & $\begin{array}{c}\text { Segarra } \\
\text { Horta-Guinardó (BCN) } \\
\text { Aràn }\end{array}$ & 14.04 & 14.10 & 14.00 \\
\hline 8 & $\begin{array}{c}\text { Baix Camp } \\
\text { Cerdanya } \\
\text { Anoia }\end{array}$ & 14.27 & 14.40 & 14.10 \\
\hline 9 & $\begin{array}{l}\text { Ribera d'Ebre } \\
\text { Segrià } \\
\text { Sant Martí (BCN) }\end{array}$ & 14.44 & 14.51 & 14.40 \\
\hline 10 & $\begin{array}{l}\text { Conca de Barberà } \\
\text { Alt Camp } \\
\text { Pallars Jussà }\end{array}$ & 14.70 & 14.80 & 14.60 \\
\hline 11 & $\begin{array}{c}\text { Berguedà } \\
\text { Moianès } \\
\text { Pallars Sobirà }\end{array}$ & 14.90 & 14.90 & 14.90 \\
\hline 12 & $\begin{array}{c}\text { Pla de l'Estany } \\
\text { Osona } \\
\text { Tarragonès }\end{array}$ & 15.07 & 15.10 & 15.00 \\
\hline 13 & $\begin{array}{c}\text { Alta Ribagorça } \\
\text { Bages } \\
\text { Garrotxa }\end{array}$ & 15.27 & 15.40 & 15.20 \\
\hline 14 & $\begin{array}{c}\text { Garraf } \\
\text { Gironès } \\
\text { Sant Adrià del Besos }\end{array}$ & 15.60 & 15.60 & 15.60 \\
\hline 15 & $\begin{array}{c}\text { Maresme } \\
\text { Alt Penedès } \\
\text { Vallès Oriental }\end{array}$ & 15.83 & 15.90 & 15.70 \\
\hline 16 & $\begin{array}{c}\text { Badalona } \\
\text { L'Hospitalet de Llobregat } \\
\text { Ripollès }\end{array}$ & 16.23 & 16.50 & 15.90 \\
\hline 17 & $\begin{array}{c}\text { Vallès Occidental } \\
\text { Baix Llobregat } \\
\text { Vila de Gràcia (BCN) }\end{array}$ & 17.43 & 18.90 & 16.50 \\
\hline
\end{tabular}




\begin{tabular}{|l|l|l|l|l|}
\hline 18 & $\begin{array}{l}\text { Eixample (BCN) } \\
\text { Les Corts (BCN) } \\
\text { Sarrià-Sant Gervasi (BCN) }\end{array}$ & 26.25 & 33.60 & 19.91 \\
\hline
\end{tabular}

Table 2A. Obesity rates and population size in sanitary regions in Catalonia.

\begin{tabular}{|c|ccc|}
\hline \multicolumn{1}{|c}{ Obesity } & Population & \% of Population with Overweight & Sanitary Regions \\
\hline \multirow{3}{*}{0} & 607,166 & $15 \%$ & Girona \\
& 359,215 & $15 \%$ & Catalunya Central \\
\cline { 2 - 4 } & $3,566,952$ & $14 \%$ & Barcelona \\
\hline \multirow{4}{*}{1} & 258,448 & $15.4 \%$ & Lleida \\
& 52,419 & $16 \%$ & Alt Pirineu i Aran \\
& 428,161 & $17 \%$ & Camp de Tarragona \\
& 128,936 & $19 \%$ & Terres de l'Ebre \\
\hline
\end{tabular}

Source: Catalan Health Survey (ESCA). 